\title{
Surgical and oncological efficacy of laparoscopic-assisted total gastrectomy versus open total gastrectomy for gastric cancer by propensity score matching: a retrospective comparative study
}

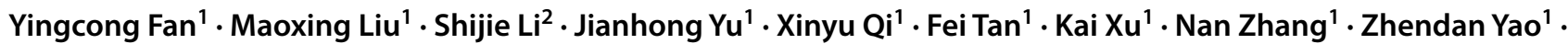 \\ Hong Yang ${ }^{1} \cdot$ Chenghai Zhang $^{1} \cdot$ Jiadi Xing ${ }^{1} \cdot$ Zaozao Wang $^{1} \cdot$ Ming Cui $^{1} \cdot$ Xiangqian Su $^{1}$ (D)
}

Received: 7 August 2020 / Accepted: 12 December 2020 / Published online: 7 January 2021

(c) The Author(s) 2021

\begin{abstract}
Purpose The application of laparoscopic-assisted total gastrectomy (LATG) for resectable gastric cancer (GC) remains controversial compared with open total gastrectomy (OTG), especially for advanced gastric cancer (AGC) patients according to the inconsistent results demonstrated in the previous studies. The aim of this study was to evaluate the short-term and long-term outcomes between LATG and OTG in a population with more than $80 \%$ AGC patients by applying propensity score matching (PSM) method.

Methods The data of 365 clinical stage I-III GC cases who underwent total gastrectomy with D2 lymphadenectomy were retrospectively collected from January 2011 to April 2018 in the Department of Gastrointestinal Surgery IV of Peking University Cancer Hospital. Propensity scores were generated through taking all covariates into consideration and 131 pairs of patients receiving either LATG or OTG were matched. Intraoperative, postoperative, and survival parameters were compared in the matched groups accordingly. Risk factors for postoperative complications and overall survival were further analyzed. Results Patient characteristics in the LATG and OTG groups were well balanced after PSM. LATG showed advantages with respect to shorter time to ambulation, first flatus, and first whole liquid diet intake. No significant differences were found between the two groups with regard to postoperative complications as well as overall survival in terms of different pathological stage. Older age was found as an independent risk factor for postoperative complications, and pathological stage for overall survival as well.

Conclusion LATG appears to have comparable surgical and oncological safety with OTG by experienced surgeons.
\end{abstract}

Keywords Gastric cancer · Laparoscopic-assisted total gastrectomy · Open total gastrectomy $\cdot$ Surgical safety $\cdot$ Oncological efficacy $\cdot$ Propensity score matching

Yingcong Fan, Maoxing Liu and Shijie Li contributed equally to this work.

Zaozao Wang

zaozao83630@bjmu.edu.cn

Ming Cui

cuiming@bjmu.edu.cn

$\triangle$ Xiangqian $\mathrm{Su}$

suxiangqian@bjmu.edu.cn

1 Key Laboratory of Carcinogenesis and Translational Research (Ministry of Education), Department of Gastrointestinal Surgery IV, Peking University Cancer Hospital and Institute, Beijing 100142, China

2 Key Laboratory of Carcinogenesis and Translational Research (Ministry of Education), Department of Endoscopy, Peking University Cancer Hospital and Institute, Beijing 100142, China

\section{Introduction}

Despite a slight drop of incidence, gastric cancer (GC) remains the fifth most common malignancy and the third main causes of cancer death worldwide (Bray et al. 2018). Radical surgery plays an essential role in GC treatment for resectable cases. In the recent years, minimally invasive surgery has gained popularity due to its less invasive nature and its faster postoperative recovery (Herrera-Almario and Strong 2016; Pugliese et al. 2010). To date, several international cooperative multicenter randomized controlled trials (RCT) have demonstrated the short-term safety and longterm efficacy of laparoscopic-assisted distal gastrectomy (LADG) for distal GC (Hiki et al. 2018; Hu et al. 2016; Katai et al. 2010; Kim et al. 2016; Park et al. 2018; Wang 
et al. 2019; Yu et al. 2019). In many experienced institutions, laparoscopic surgery is a mature technique and optional approach, instead of conventional open surgery, for distal gastrectomy.

Nevertheless, compared with LADG, studies which provide convincing data to prove the feasibility and safety of laparoscopic-assisted total gastrectomy (LATG) remain insufficient. JCOG1401 and KLASS03 were two singlearm multicenter prospective studies conducted in Japan and Korea which aimed to evaluate the surgical safety of laparoscopic total gastrectomy (LTG) or laparoscopic-assisted total/proximal gastrectomy (LATG/LAPG) for patients with clinical stage I GC (Hyung et al. 2019; Kataoka et al. 2016). While the postoperative complication rates differed greatly. JCOG1401 trial reported a $29.1 \%$ incidence of in-hospital grade III-IV adverse events, which was really higher than KLASS03 study with $9.4 \%$ grade III or higher complication rate (Hyung et al. 2019; Katai et al. 2019). Owing to the difficulty of standard systematic D2 lymphadenectomy and esophagojejunostomy in total gastrectomy (TG), the risk of postoperative complications for advanced gastric cancer (AGC) patients underwent LATG may be even higher, while no RCTs have been launched to evaluate the feasibility and oncological efficacy of LATG for AGC till now. Besides, the results from retrospective studies also reported contradictory results. Although some studies demonstrated that LATG was associated with better intraoperative parameters and lower incidence of postoperative complications (Etoh et al. 2018; Lin et al. 2017), other studies found anastomotic leakage occurred more frequently in LATG than OTG group, even after taking the effect of learning curve into consideration (Sakamoto et al. 2019; Shim et al. 2013). More studies are still needed to confirm the non inferiority of LATG to OTG, especially for AGC patients. Therefore, we retrospectively investigated data from 365 patients with a majority of AGC cases who underwent LATG or OTG in the Department of Gastrointestinal Surgery IV of Peking University Cancer Hospital, comprehensively analyzed the data by using propensity score matching (PSM) method, and reported surgical safety as well as oncological efficacy between the two groups, in addition with risk factors for post-operative complications and overall survival.

\section{Patients and methods}

\section{Patients}

We retrospectively collected data from 365 patients who were diagnosed as clinical stage I-III GC and received radical TG between January 2011 and April 2018. The exclusive criteria were as follows: (1) peritoneum implanting confirmed in surgery $(n=2)$; (2) combined resection due to tumor invasion $(n=5)$; (3) remnant gastric cancer $(n=3)$; (4) incomplete clinical records $(n=10)$. The remaining 345 cases, with 198 and 147 cases undergoing LATG and OTG, respectively, were involved in this analysis. Then, 131 pairs of patients were matched from the two groups after PSM (Fig. 1 study flow diagram).

The clinicopathological characteristics were collected from surgical and nursing records as well as pathological reports. Diagnosis of GC along with clinical TNM stage were confirmed before surgery based on the preoperative examinations, including esophagogastroduodenoscopy with biopsy, chest, and abdominal CT scan, together with endoscopic ultrasonography. Comorbidities according to the American Society of Anesthesiologist (ASA) system were scored to evaluate the general condition of patients
Fig. 1 Study flow diagram. 365 patients were diagnosed with gastric cancer. 345 cases met the inclusion and exclusion criteria. After propensity score matching (PSM), there were 131 cases in each group. LATG laparoscopic-assisted total gastrectomy, $O T G$ open total gastrectomy, $B M I$ body mass index, ASA American Society of Anesthesiologist, $N A C$ neoadjuvant chemotherapy

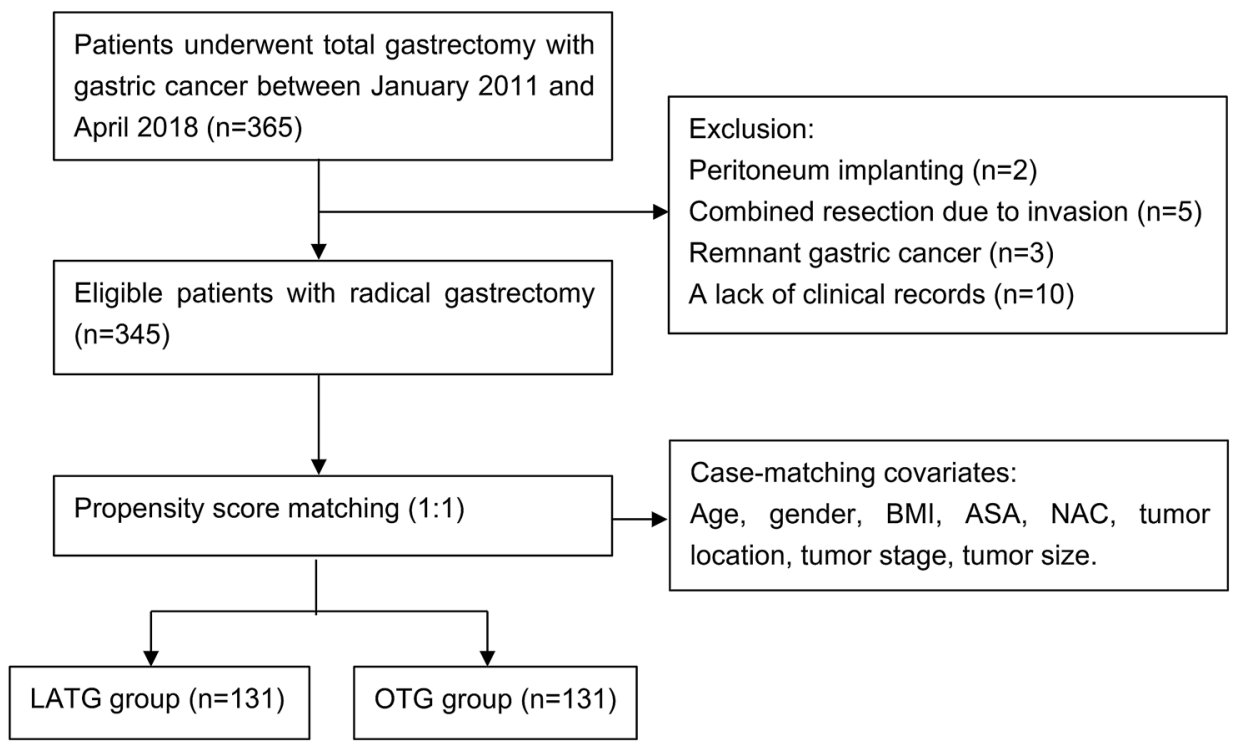


(Davenport et al. 2006). Clinical I-III stage GC patients with tumors located in the upper, middle, or whole stomach had undergone radical TG with standard D2 lymph node dissection, in line with the Japanese Gastric Cancer Treatment Guidelines (Japanese Gastric Cancer Association 2017). Besides, 37 patients received neo-adjuvant chemotherapy (NAC) with Xelox or Sox regimens before radical surgery due to their locally advanced clinical stage. Pathological stage was diagnosed according to the 8th Union for International Cancer Control (UICC)/American Joint Committee on Cancer (AJCC) staging system (Sano et al. 2017) after surgery. Patients with pathological stage $\geq \mathrm{pT} 2$ or $\mathrm{pN}$ (positive) were treated with Xelox or Sox regimens for at least 4-8 cycles as adjuvant chemotherapy. Patients were well informed about the advantages and disadvantages of LATG and OTG before making their willing choices. Informed consent was obtained from each patient. This program was approved by the Research Ethics Committee of Peking University Cancer Hospital.

\section{Operative techniques}

Radical gastrectomy with standard D2 regional lymphadenectomy was performed in line with the Japanese Gastric Cancer Treatment Guidelines (Japanese Gastric Cancer Association 2017). Roux-en-Y esophagojejunostomy reconstruction was routinely performed in surgery. Splenic hilar lymph node dissection was not routinely performed. For LATG, five trocars were inserted with unrestricted location. Gastrectomy and lymph nodes dissection were performed under the assistance of laparoscopy. Then, an incision about 5-7 $\mathrm{cm}$ was made in the midline of the upper abdomen to perform the esophagojejunostomy reconstruction procedure. In contrast, an incision about $15-20 \mathrm{~cm}$ by laparotomy was required in the performance of OTG surgery from start to finish. All the operations were conducted by the same experienced surgeon together with two assistants, who had already conducted at least 50 cases of LATG and OTG operations, respectively.

\section{Definitions}

Postoperative morbidity and mortality were analyzed within 30 days after surgery. The postoperative complications, graded by the Clavien-Dindo classification system (Dindo et al. 2004), were divided into surgical related and non-surgical related complications. Surgical related complications were composed of pancreatic leakage, intra-abdominal bleeding, anastomotic bleeding, surgical site infection, seroperitoneum, intra-abdominal abscess, intestinal obstruction, intestinal fistula, anastomotic leakage, and lymphorrhagia. Although pulmonary infection, pleural effusion, cardiovascular dysfunction, and other problems comprised non surgical related complications. The overall survival was defined as the period from surgery to death or final follow-up date.

\section{Follow-up}

The follow-up staffs in our department conducted regular follow-up and managed postoperative re-examination for patients at indicated time point, namely every 3 months for the first 2 years, 6 months for the following 3 years and 12 months after the first 5 years. All patients were followed until death or July 2020, ranging from 3 to 91 months.

\section{Propensity score matching and statistical analysis}

To minimize the effect of selection bias of non randomized trial, PSM method was applied to balance the unevenly distributed patient baseline characteristics in the present study. Individual propensity scores were generated through a logistic regression model which included the following covariates: age, gender, body mass index (BMI), ASA score, NAC, macroscopic appearance, tumor location, tumor size, histological grade, and pathological TNM (pTNM) stage. Then, patients undergoing LATG or OTG were paired by a 1:1 nearest available score matching algorithm with a caliper width of 0.02 (Austin 2009; Ralph 1998; Rosenbaum 1983). After matching, balanced distribution of each covariate between the two groups was confirmed. The matched LATG and OTG groups were compared subsequently to estimate treatment effect of different surgical approaches.

Values of continuous variables were represented as $\bar{X} \pm S D$, and values of categorical variables were represented as frequencies and percentages. Differences between groups were examined by using Student's $t$ test, $\chi^{2}$ test or Fisher's exact test where appropriate. Logistic regression was used to figure out risk factors for postoperative complications in univariate and multivariate analyses. Kaplan-Meier and log-rank test were performed to identify the difference of overall survival between the two groups according to different pathological stages. Cox proportional hazards regression model was used to determine the risk factors for survival. The items with $P$ values less than 0.1 in the univariate analysis were adopted in the multivariate analysis in both regression equations. $P$ values less than 0.05 , derived from two-tailed tests, were considered statistically significant. All statistical analyses were performed with SPSS v. 25.0 (SPSS Inc., Chicago, IL, USA).

\section{Results}

\section{Patients characteristics}

The clinicopathological characteristics of patients receiving TG, both before and after PSM, were presented in Table 1 . 
Before PSM, there were 345 patients in total, including 198 LATG cases and 147 OTG cases. There were significant differences between the two groups for the following patient characteristics: BMI $(P=0.040)$, NAC $(P=0.028)$ and tumor size $(P=0.040)$. After PSM, both LATG and OTG groups consisted of 131 patients each, and all the baseline parameters were well balanced between the two groups.

\section{Intraoperative and recovery outcomes}

Before PSM, no significant differences were found between the two groups. After PSM, the LATG group showed significant advantages in the following items: reduced time to ambulation ( 21.9 vs. $24.9 \mathrm{~h}, P=0.016$ ), faster first flatus ( 2.8 vs. 3.3 days, $P=0.013$ ), and shorter time to whole liquid diet intake (9.1 vs. 10.6 days, $P=0.048$ ) (Table 2). In addition, LATG group showed less blood loss in surgery $(67.3 \pm 45.9$ vs. $99.2 \pm 119.1 \mathrm{ml}, P=0.102$ ) compared with OTG group, although without significant statistical difference.

\section{Postoperative complications}

Both before and after PSM, no significant differences were found between the groups in terms of postoperative adverse events (Table 3). After PSM, the total number of postoperative complications were $28(21.4 \%)$ and $20(15.3 \%)$ in the LATG and OTG group respectively, including surgical related complications $(19,14.5 \%$ vs. $11,8.4 \%, P=0.121)$ and the non surgical related complications $(15,11.5 \%$ vs. $12,9.2 \%, P=0.542)$. The incidence of severe complications showed no significant statistical difference, which referred to the complication severity no less than Grade III according to the Clavien-Dindo classification system, between the two groups.

\section{Univariate and multivariate analysis of risk factors associated with postoperative complications}

Univariate and multivariate logistic regression analyses were performed to analyze the risk factors for postoperative complications among the matched cases. In the univariate analysis, age $(P=0.027)$, gender $(P=0.059)$, operation time $(P=0.005)$, and blood loss in surgery $(P=0.031)$ were closely associated with postoperative morbidity. In the multivariate analysis, age $(P=0.038)$ was identified as an independent risk factor for postoperative complications (Table 4).

\section{Survival}

The overall survival of patients in LATG and OTG groups according to different pathological stages were presented by Kaplan-Meier curves both before and after PSM (Fig. 2).
The median follow-up period was 36 (range 3-91) months. There were no significant differences between the LATG and OTG groups in terms of the same pathological stage. Before PSM, the cumulative survival rate between LATG and OTG in each stage was comparable (Stage I log-rank $P=0.891$, Stage II log-rank $P=0.587$, Stage III log-rank $P=0.907$ ). After PSM, the overall survival rates were still similar between the two groups in each stage respectively (Stage I log-rank $P=0.299$, Stage II log-rank $P=0.609$, Stage III $\log$-rank $P=0.815$ ). However, the long-term survival rates differed significantly when it was stratified by different stages in either surgical types. Before PSM, the cumulative survival rates decreased gradually with the increased pathological stage of patients in both LATG and OTG groups (LATG log-rank $P=0.002$, OTG log-rank $P=0.013$ ). The results were similar in both groups after PSM (LATG logrank $P=0.022$, OTG log-rank $P=0.020$ ), indicating a close correlation between survival and pathological stage (data not shown).

\section{Univariate and multivariate analysis of risk factors associated with overall survival}

In the univariate analysis, we found BMI $(P=0.089)$, pTNM stage $(P<0.001)$, vascular cancer embolus $(P=0.069)$, CEA $(P=0.004)$ and CA72-4 $(P=0.002)$ were closely associated with overall survival among the matched cases (Table 5). Further, pTNM stage $(P=0.003)$ was identified as an independent risk factor for overall survival in the multivariate analysis, the hazard ratio of stage III was 2.678 -fold as much as stage I/II, with $95 \%$ confidence interval of $1.385-5.177$ (Fig. 3).

\section{Discussion}

Studies indicate that laparoscopic radical gastrectomy is a feasible alternative or optional therapy for early stage of GC; it is less invasive and is associated with faster postoperative recovery than conventional open surgery (Sakuramoto et al. 2013; Zeng et al. 2012). A Korean nationwide KLASS-01 clinical trial demonstrated that LADG surgery was as safe as ODG surgery and had a lower rate of wound complications for stage I GC patients (Kim et al. 2016). The nationwide JCOG0912 study in Japan reached similar conclusion (Nakamura et al. 2013). Further, a Japanese nationwide JCOG0703 study confirmed the short-term safety and longterm efficiency of LADG, comparing with open surgery in stage I GC (Hiki et al. 2018; Katai et al. 2010). As for locally advanced gastric cancer, CLASS-01 and COACT 1001 trials indicated that experienced surgeons perform radical LADG safely and feasibly, and the latest follow-up data suggested a 
Table 1 Comparison of clinicopathological features of LATG and OTG groups

\begin{tabular}{|c|c|c|c|c|c|c|}
\hline \multirow[t]{2}{*}{ Characteristics } & \multicolumn{2}{|c|}{ All patients $(n=345)$} & \multirow[t]{2}{*}{$P$} & \multicolumn{2}{|c|}{ Patients after propensity matching $(n=262)$} & \multirow[t]{2}{*}{$P$} \\
\hline & LATG $(n=198)$ & OTG $(n=147)$ & & LATG $(n=131)$ & OTG $(n=131)$ & \\
\hline Age (year) $n(\%)$ & & & 0.727 & & & 0.711 \\
\hline$<60$ & $94(47.5)$ & $67(45.6)$ & & $59(45.0)$ & $62(47.3)$ & \\
\hline$\geq 60$ & $104(52.5)$ & $80(54.4)$ & & $72(55.0)$ & $69(52.7)$ & \\
\hline Gender $n(\%)$ & & & 0.327 & & & 0.887 \\
\hline Female & $41(20.7)$ & $37(25.2)$ & & $33(25.2)$ & $34(26.0)$ & \\
\hline Male & $157(79.3)$ & $110(74.8)$ & & $98(74.8)$ & $97(74.0)$ & \\
\hline $\mathrm{BMI}\left(\mathrm{kg} / \mathrm{m}^{2}\right) n(\%)$ & & & 0.040 & & & 0.409 \\
\hline$<30$ & $195(98.5)$ & 139 (94.6) & & $129(98.5)$ & $127(96.9)$ & \\
\hline$\geq 30$ & $3(1.5)$ & $8(5.4)$ & & $2(1.5)$ & $4(3.1)$ & \\
\hline NAC $n(\%)$ & & & 0.028 & & & 0.679 \\
\hline No & $183(92.4)$ & $125(85.0)$ & & $117(89.3)$ & $119(90.8)$ & \\
\hline Yes & $15(7.6)$ & $22(15.0)$ & & $14(10.7)$ & $12(9.2)$ & \\
\hline ASA score $n(\%)$ & & & 0.727 & & & 1.000 \\
\hline$<3$ & $184(92.9)$ & $138(93.9)$ & & $122(93.1)$ & $122(93.1)$ & \\
\hline$\geq 3$ & $14(7.1)$ & $9(6.1)$ & & $9(6.9)$ & $9(6.9)$ & \\
\hline Macroscopic appearance $n(\%)$ & & & 0.086 & & & 0.679 \\
\hline Non-linitis plastica & $170(85.9)$ & $135(91.8)$ & & $117(89.3)$ & $119(90.8)$ & \\
\hline Linitis plastica & $28(14.1)$ & $12(8.2)$ & & $14(10.7)$ & $12(9.2)$ & \\
\hline Tumor location $n(\%)$ & & & 0.228 & & & 0.714 \\
\hline Upper & $132(66.7)$ & $104(70.7)$ & & $93(71.0)$ & $90(68.7)$ & \\
\hline Middle & $38(19.2)$ & $31(21.1)$ & & $24(18.3)$ & $29(22.1)$ & \\
\hline Total & $28(14.1)$ & $12(8.2)$ & & $14(10.7)$ & $12(9.2)$ & \\
\hline \multicolumn{7}{|l|}{ Tumor size $(\mathrm{cm})$} \\
\hline Long diameter & $4.9 \pm 2.9$ & $4.5 \pm 2.5$ & 0.457 & $4.6 \pm 2.6$ & $4.7 \pm 2.6$ & 0.867 \\
\hline Short diameter & $1.9 \pm 2.3$ & $1.4 \pm 1.4$ & 0.040 & $1.4 \pm 1.5$ & $1.5 \pm 1.5$ & 0.462 \\
\hline Histologic type $n(\%)$ & & & 0.222 & & & 0.669 \\
\hline Well differentiated & $5(2.5)$ & $4(2.7)$ & & $2(1.5)$ & $4(3.1)$ & \\
\hline Moderate & $108(54.5)$ & $70(47.6)$ & & $66(50.4)$ & $67(51.1)$ & \\
\hline Poor & $85(42.9)$ & $72(49.0)$ & & $63(48.1)$ & $59(45.0)$ & \\
\hline Undifferentiated & $0(0)$ & $1(0.7)$ & & $0(0)$ & $1(0.8)$ & \\
\hline pT stage $n(\%)$ & & & 0.819 & & & 0.485 \\
\hline $\mathrm{T} 1$ & 23 (11.6) & $18(12.2)$ & & $12(9.2)$ & $16(12.2)$ & \\
\hline $\mathrm{T} 2$ & $25(12.6)$ & $15(10.2)$ & & $20(15.3)$ & $13(9.9)$ & \\
\hline T3 & $84(42.4)$ & $64(43.5)$ & & $59(45.0)$ & $55(42.0)$ & \\
\hline $\mathrm{T} 4$ & $66(33.4)$ & $50(34.1)$ & & $40(30.5)$ & $47(35.9)$ & \\
\hline pN stage $n(\%)$ & & & 0.187 & & & 0.651 \\
\hline No & $83(41.9)$ & $49(33.3)$ & & $48(36.6)$ & $44(33.6)$ & \\
\hline N1 & 29 (14.6) & $22(15.0)$ & & $19(14.5)$ & $19(14.5)$ & \\
\hline $\mathrm{N} 2$ & $39(19.7)$ & $39(26.5)$ & & $31(23.7)$ & $34(26.0)$ & \\
\hline N3 & $47(23.7)$ & $37(25.2)$ & & $33(25.2)$ & $34(26.0)$ & \\
\hline pTNM stage $n(\%)$ & & & 0.435 & & & 0.422 \\
\hline IA & $22(11.1)$ & $15(10.2)$ & & $14(10.7)$ & $11(8.4)$ & \\
\hline IB & $16(8.1)$ & $13(8.8)$ & & $10(7.6)$ & $12(9.2)$ & \\
\hline IIA & $40(20.2)$ & $23(15.6)$ & & $25(19.1)$ & $20(15.3)$ & \\
\hline IIB & $30(15.2)$ & $17(11.6)$ & & $16(12.2)$ & $20(15.3)$ & \\
\hline IIIA & $41(20.7)$ & $42(28.6)$ & & $28(21.4)$ & $39(29.8)$ & \\
\hline IIIB & $31(15.7)$ & $18(12.2)$ & & $24(18.3)$ & $14(10.7)$ & \\
\hline IIIC & $18(9.1)$ & $19(12.9)$ & & 14 (10.7) & $15(11.5)$ & \\
\hline
\end{tabular}

Bold and italic values are statistically significant $p<0.05$

$L A T G$ laparoscopic-assisted total gastrectomy, OTG open total gastrectomy, BMI body mass index, ASA American Society of Anesthesiologist, $N A C$ neoadjuvant chemotherapy 
Table 2 Intra-operative and recovery outcomes of LATG and OTG groups

\begin{tabular}{|c|c|c|c|c|c|c|}
\hline \multirow[t]{2}{*}{ Variables } & \multicolumn{2}{|c|}{ All patients $(n=345)$} & \multirow[t]{2}{*}{$P$} & \multicolumn{2}{|c|}{$\begin{array}{l}\text { Patients after propensity matching } \\
(n=262)\end{array}$} & \multirow[t]{2}{*}{$P$} \\
\hline & LATG $(n=198)$ & OTG $(n=147)$ & & LATG $(n=131)$ & OTG $(n=131)$ & \\
\hline Operation time (min) & $258.6 \pm 55.8$ & $257.7 \pm 54.4$ & 0.801 & $253.7 \pm 50.9$ & $257.5 \pm 55.9$ & 0.940 \\
\hline Blood loss (ml) & $81.6 \pm 69.2$ & $99.5 \pm 118.8$ & 0.962 & $67.3 \pm 45.9$ & $99.2 \pm 119.1$ & 0.102 \\
\hline No. of dissected lymph nodes & $32.6 \pm 11.8$ & $33.5 \pm 13.4$ & 0.545 & $33.2 \pm 12.7$ & $34.2 \pm 13.6$ & 0.211 \\
\hline Time to ambulation (h) & $23.7 \pm 20.5$ & $24.6 \pm 19.6$ & 0.087 & $21.9 \pm 15.3$ & $24.9 \pm 20.2$ & 0.016 \\
\hline Time to resume bowel sound (D) & $3.8 \pm 1.5$ & $3.6 \pm 1.4$ & 0.262 & $3.5 \pm 1.3$ & $3.6 \pm 1.4$ & 0.497 \\
\hline Time to first flatus (D) & $3.1 \pm 1.1$ & $3.3 \pm 1.0$ & 0.537 & $2.8 \pm 0.9$ & $3.3 \pm 1.0$ & 0.013 \\
\hline Time to whole liquid diet (D) & $9.3 \pm 3.1$ & $10.4 \pm 6.6$ & 0.198 & $9.1 \pm 3.0$ & $10.6 \pm 6.9$ & 0.048 \\
\hline Postoperative hospital stay (D) & $11.7 \pm 6.3$ & $11.1 \pm 5.3$ & 0.441 & $11.6 \pm 7.1$ & $11.2 \pm 5.5$ & 0.814 \\
\hline
\end{tabular}

Bold and italic values are statistically significant $p<0.05$

$L A T G$ laparoscopic-assisted total gastrectomy, $O T G$ open total gastrectomy, $D$ days,

Table 3 Postoperative complications of LATG and OTG groups

\begin{tabular}{|c|c|c|c|c|c|c|}
\hline \multirow[t]{2}{*}{ Variable } & \multicolumn{2}{|c|}{ All patients $(n=345)$} & \multirow[t]{2}{*}{$P$} & \multicolumn{2}{|c|}{ Patients after propensity matching $(n=262)$} & \multirow[t]{2}{*}{$P$} \\
\hline & LATG $(n=198)$ & OTG $(n=147)$ & & LATG $(n=131)$ & OTG $(n=131)$ & \\
\hline Total complications $n(\%)$ & $42(21.2)$ & $24(16.3)$ & 0.254 & $28(21.4)$ & $20(15.3)$ & 0.201 \\
\hline Surgical related $n(\%)$ & $28(14.1)$ & $13(8.8)$ & 0.133 & $19(14.5)$ & $11(8.4)$ & 0.121 \\
\hline Pancreatic leakage & $1(0.5)$ & $2(1.4)$ & 0.577 & $1(0.8)$ & $2(1.5)$ & 1.000 \\
\hline Intra-abdominal bleeding & $5(2.5)$ & $0(0)$ & 0.074 & $3(2.3)$ & $0(0)$ & 0.247 \\
\hline Anastomotic bleeding & $6(3.0)$ & $2(1.4)$ & 0.475 & $5(3.8)$ & $2(1.5)$ & 0.447 \\
\hline Surgical site infection & $1(0.5)$ & $2(1.4)$ & 0.577 & $1(0.8)$ & $2(1.5)$ & 1.000 \\
\hline Seroperitoneum & $4(2.0)$ & $1(0.7)$ & 0.399 & $2(1.5)$ & $1(0.8)$ & 1.000 \\
\hline Intra-abdominal abscess & $3(1.5)$ & $1(0.7)$ & 0.639 & $2(1.5)$ & $1(0.8)$ & 1.000 \\
\hline Intestinal obstruction & $2(1.0)$ & $1(0.7)$ & 1.000 & $1(0.8)$ & $0(0)$ & 1.000 \\
\hline Intestinal fistula & $3(1.5)$ & $2(1.4)$ & 1.000 & $3(2.3)$ & $2(1.5)$ & 1.000 \\
\hline Anastomotic leakage & $8(4.0)$ & $2(1.4)$ & 0.199 & $6(4.6)$ & $1(0.8)$ & 0.120 \\
\hline Lymphorrhagia & $4(2.0)$ & $0(0)$ & 0.139 & $2(1.5)$ & $0(0)$ & 0.498 \\
\hline Non-surgical related $n(\%)$ & $23(11.6)$ & $15(10.2)$ & 0.679 & $15(11.5)$ & $12(9.2)$ & 0.542 \\
\hline Pulmonary infection & $16(8.1)$ & $13(8.8)$ & 0.801 & $11(8.4)$ & $10(7.6)$ & 0.820 \\
\hline Pleural effusion & $17(8.6)$ & $9(6.1)$ & 0.391 & $9(6.9)$ & $6(4.6)$ & 0.425 \\
\hline Cardiovascular system & $3(1.5)$ & $1(0.7)$ & 0.639 & $3(2.3)$ & $0(0)$ & 0.247 \\
\hline Others & $0(0)$ & $1(0.7)$ & 0.184 & $20(15.3)$ & $18(13.7)$ & 0.213 \\
\hline \multicolumn{7}{|c|}{ Clavien-Dindo classification $n(\%)$} \\
\hline$<3$ & $30(15.2)$ & $21(14.3)$ & 0.823 & $20(15.3)$ & $18(13.7)$ & 0.726 \\
\hline$\geq 3$ & $12(6.1)$ & $3(2.0)$ & 0.070 & $8(6.1)$ & $2(1.5)$ & 0.053 \\
\hline
\end{tabular}

$L A T G$ laparoscopic-assisted total gastrectomy, $O T G$ open total gastrectomy

comparable 3-year DFS of LADG to ODG (Hu et al. 2016; Park et al. 2018; Wang et al. 2019; Yu et al. 2019).

However, owing to the extended lymph node dissection and complex digestive reconstruction that are performed in LATG, whether the surgical and oncological outcomes of LATG are not inferior to OTG remains controversial. When compared with LADG, whose standard D2 lymphadenectomy includes nos. 1, 3, 4sb, 4d, 5, 6, 7, 8a, 9, 11p, 12a,
LATG requires additional resection of nos. 2, 4sa, and 11d lymph nodes. For the gastroesophageal junction adenocarcinoma invading the esophagus, resection of No. 110, 111, 19 and 20 lymph nodes are further required to obtain a sufficient resection margin (Japanese Gastric Cancer Association 2017). Moreover, considering the limited space, complex lymph node metastatic pathways and complicated vessels around the cardia, the lymph node dissection of lower 
Table 4 Univariate and multivariate analyses of risk factors of postoperative complications after PSM

\begin{tabular}{|c|c|c|c|c|c|c|}
\hline \multirow[t]{2}{*}{ Variables } & \multicolumn{2}{|c|}{ Postoperative complications } & \multirow{2}{*}{$\begin{array}{l}\text { Univariate } \\
\text { analysis } P\end{array}$} & \multicolumn{3}{|c|}{ Multivariate analysis } \\
\hline & No $(n=214)$ & Yes $(n=48)$ & & OR & $95 \% \mathrm{CI}$ & $P$ \\
\hline \multicolumn{7}{|l|}{ Surgical approach $n(\%)$} \\
\hline OTG & $111(51.9)$ & $20(41.7)$ & & & & \\
\hline LATG & $103(48.1)$ & $28(58.3)$ & 0.203 & & & \\
\hline \multicolumn{7}{|l|}{ Age (years) $n(\%)$} \\
\hline$<60$ & $105(49.1)$ & $15(31.2)$ & & 1 [Reference] & & \\
\hline$\geq 60$ & $109(50.9)$ & $33(68.8)$ & 0.027 & 2.082 & $1.042-4.160$ & 0.038 \\
\hline \multicolumn{7}{|l|}{ Gender $n(\%)$} \\
\hline Female & $154(72.0)$ & $7(14.6)$ & & 1 [Reference] & & \\
\hline Male & $60(28.0)$ & $41(85.4)$ & 0.059 & 1.790 & $0.728-4.403$ & 0.205 \\
\hline \multicolumn{7}{|l|}{$\mathrm{BMI} n(\%)$} \\
\hline$<30$ & $209(97.7)$ & $47(97.9)$ & & & & \\
\hline$\geq 30$ & $5(2.3)$ & $1(2.1)$ & 0.916 & & & \\
\hline \multicolumn{7}{|l|}{ ASA $n(\%)$} \\
\hline$<3$ & $198(92.5)$ & $46(95.8)$ & & & & \\
\hline$\geq 3$ & $16(7.5)$ & $2(4.2)$ & 0.419 & & & \\
\hline \multicolumn{7}{|l|}{ NAC $n(\%)$} \\
\hline No & $191(89.3)$ & 45 (93.8) & & & & \\
\hline Yes & $23(10.7)$ & $3(6.3)$ & 0.352 & & & \\
\hline \multicolumn{7}{|l|}{ pT stage $n(\%)^{\mathrm{a}}$} \\
\hline $\mathrm{T} 1$ & $24(11.2)$ & $4(8.3)$ & & & & \\
\hline $\mathrm{T} 2$ & $27(12.6)$ & $6(12.5)$ & 0.683 & & & \\
\hline $\mathrm{T} 3$ & $93(43.5)$ & $21(43.8)$ & 0.608 & & & \\
\hline $\mathrm{T} 4$ & $70(32.7)$ & $17(35.4)$ & 0.533 & & & \\
\hline \multicolumn{7}{|l|}{$\mathrm{pN}$ stage $n(\%)^{\mathrm{a}}$} \\
\hline No & $76(35.5)$ & $16(33.3)$ & & & & \\
\hline N1 & $32(15.0)$ & $6(12.5)$ & 0.825 & & & \\
\hline $\mathrm{N} 2$ & $49(22.9)$ & $16(33.3)$ & 0.270 & & & \\
\hline N3 & $57(26.6)$ & $10(20.8)$ & 0.678 & & & \\
\hline \multicolumn{7}{|l|}{$\operatorname{pTNM} n(\%)^{\mathrm{a}}$} \\
\hline I & $35(16.4)$ & $12(25.0)$ & & & & \\
\hline II & $70(32.7)$ & $11(22.9)$ & 0.094 & & & \\
\hline III & $109(50.9)$ & $25(52.1)$ & 0.316 & & & \\
\hline \multicolumn{7}{|c|}{ Macroscopic appearance $n(\%)$} \\
\hline Non-linitis plastica & $191(89.3)$ & $45(93.8)$ & & & & \\
\hline Linitis plastica & $23(10.7)$ & $3(6.3)$ & 0.352 & & & \\
\hline Operative time (min) & $251.1 \pm 51.5$ & $275.8 \pm 57.6$ & 0.005 & 1.006 & $1.000-1.012$ & 0.054 \\
\hline Blood loss (ml) & $76.9 \pm 75.6$ & $111.2 \pm 139.8$ & 0.031 & 1.003 & $0.999-1.006$ & 0.106 \\
\hline \multicolumn{7}{|l|}{ Tumor size $(\mathrm{cm})$} \\
\hline Long diameter & $4.6 \pm 2.6$ & $4.8 \pm 2.6$ & 0.747 & & & \\
\hline Short diameter & $1.4 \pm 1.5$ & $1.4 \pm 1.2$ & 0.930 & & & \\
\hline \multicolumn{7}{|l|}{ Tumor location $n(\%)^{\mathrm{a}}$} \\
\hline Upper & $146(68.2)$ & $37(77.1)$ & & & & \\
\hline Middle & $45(21.0)$ & $8(16.7)$ & 0.405 & & & \\
\hline Total & $23(10.7)$ & $3(6.3)$ & 0.300 & & & \\
\hline \multicolumn{7}{|l|}{ Histologic type $n(\%)^{\mathrm{a}}$} \\
\hline Well differentiated & $4(1.9)$ & $2(4.2)$ & & & & \\
\hline Moderate differentiated & $109(50.9)$ & $24(50.0)$ & 0.359 & & & \\
\hline Poor differentiated & $101(47.2)$ & $21(43.8)$ & 0.329 & & & \\
\hline Undifferentiated & $0(0)$ & $1(2.1)$ & 1.000 & & & \\
\hline
\end{tabular}


mediastinum in LATG is much more challenging. In addition, esophagojejunostomy is even more difficult than gastrojejunostomy. The higher tension and less blood supply around the anastomosis after esophagojejunostomy might lead to higher risk of postoperative complications and poorer prognosis of LATG compared with LADG (Lee et al. 2012; Petersen et al. 2013; Shinohara et al. 2009). JCOG1401 has reported a $66.4 \%$ postoperative complication rate for in-hospital grade II-IV adverse events (Katai et al. 2019). Besides, several retrospective studies have demonstrated that increased anastomotic leakage and stenosis were more frequently observed in LATG (Sakamoto et al. 2019; Petersen et al. 2013). Esophagojejunal anastomotic leakage has been considered as one of the most serious complications after TG. It not only leads to immediate clinical consequences, such as prolonged hospital stay, increased mortality and elevated surgery-related costs, but also affects the longterm outcomes, including poorer quality of life, increased recurrence rate, and decreased overall survival (Kofoed et al. 2015; Nagasako et al. 2012; Sierzega et al. 2010; Yoo et al. 2011). Moreover, oncological safety seems not to be the concern of current prospective research, it was even not set as an endpoint in CLASS02 trial, whose primary and secondary endpoints were all focus on surgical safety between LTG and OTG groups for clinical stage I gastric cancer patients (He et al. 2018). In order to provide more clues to this inconclusive issue, retrospective data were collected and analyzed by using PSM in the present study.

Among the matched cases after PSM, the results demonstrated that the LATG group had a faster postoperative recovery compared with OTG group, especially in relation to the following measures: shorter interval to ambulation, faster first flatus, and reduced time to whole liquid diet intake. This result is in accordance with studies reporting favorable short-term outcomes of LADG surgery and highlights the advantages of minimally invasive surgery (Hu et al. 2016; Kim et al. 2016; Wang et al. 2019). Besides, no significant differences were observed in terms of postoperative adverse
Fig. 2 Cumulative survival rates of both LATG and OTG groups according to pathological stages (I, II, III). a, b The cumulative survival rates for pathological stage I were similar between LATG and OTG groups both before PSM $(P=0.891)$ and after PSM $(P=0.299)$. c, $\mathbf{d}$ The cumulative survival rates for pathological stage II were similar between LATG and OTG groups both before PSM $(P=0.587)$ and after PSM $(P=0.609)$. e, $\mathbf{f}$ The cumulative survival rates for pathological stage III were similar between LATG and OTG groups both before PSM $(P=0.907)$ and after PSM $(P=0.815)$. LATG laparoscopic-assisted total gastrectomy, OTG open total gastrectomy, PSM propensity score matching, $p T N M$ pathological TNM stage

events. LATG had less cases with surgical site infection, which may be due to the shorter length of incision in laparoscopic surgery than that of open surgery.

In this study, a bit more cases of intra-abdominal bleeding and anastomotic bleeding were noted in LATG compared to OTG. The following reasons may lead to higher rate of intra-abdominal bleeding in LATG. First, physical techniques, such as compression or suturing could be directly performed in open surgery by surgeons, while such procedures are highly limited in laparoscopic surgery. Operators mainly rely on thermal surgical modalities and topical sealants, such as ultrasonic dissectors, hemostasis clip, and gelatin matrix to achieve hemostasis in laparoscopic surgery (Hang et al. 2015; Lattouf et al. 2007). Second, the use of ultrasonic scalpel other than hemostasis clip to cut and close the main arteries and veins may lead to delayed intra-abdominal bleeding (Szold et al. 2018). Third, open surgery tends to cause a higher degree of activation of the clotting system than laparoscopic surgery (Diamantis et al. 2007). Therefore, medical devices, such as matrix of bovine thrombin and collagen or gelatin, polymers of cellulose backed with sponge, are highly recommended to establish a stable network for the closure of the microvascular oozing in laparoscopy (Vecchio et al. 2016).

Anastomotic bleeding is relatively rare but lethal if not treated immediately. The use of gastrointestinal staplers was necessary to perform gastrointestinal anastomosis (Vecchio
Table 4 (continued)

\begin{tabular}{|c|c|c|c|c|c|c|}
\hline \multirow[t]{2}{*}{ Variables } & \multicolumn{2}{|c|}{ Postoperative complications } & \multirow{2}{*}{$\begin{array}{l}\text { Univariate } \\
\text { analysis } P\end{array}$} & \multicolumn{3}{|c|}{ Multivariate analysis } \\
\hline & No $(n=214)$ & Yes $(n=48)$ & & OR & $95 \%$ CI & $P$ \\
\hline \multicolumn{7}{|c|}{ No. of comorbidities $n(\%)^{\mathrm{a}}$} \\
\hline 0 & $159(74.3)$ & 35 (72.9) & & & & \\
\hline 1 & $49(22.9)$ & $11(22.9)$ & 0.959 & & & \\
\hline 2 & $6(2.8)$ & $2(4.2)$ & 0.620 & & & \\
\hline
\end{tabular}

Bold and italic values are statistically significant $p<0.05$

LATG laparoscopic-assisted total gastrectomy, OTG open total gastrectomy, BMI body mass index, ASA American Society of Anesthesiologist, NAC neoadjuvant chemotherapy, OR odds ratio, CI confidence interval,

${ }^{a}$ For categorical variable, each first item of classification was used as reference in the univariate logistic regression 
A Before PSM

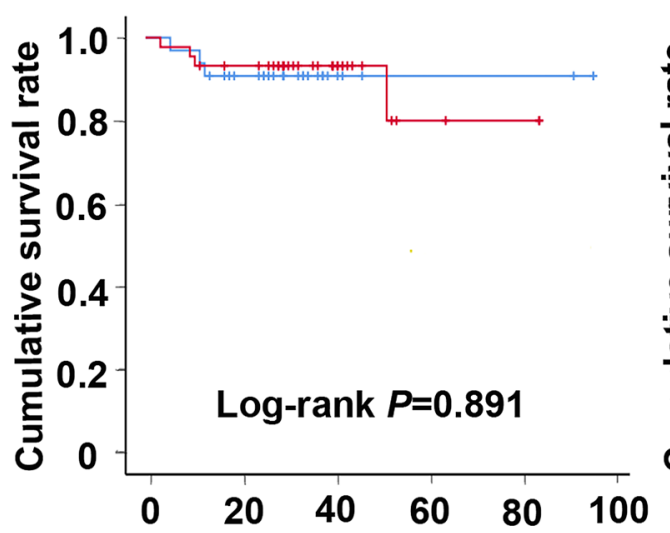

Time after operation (months)
B

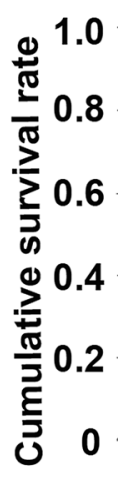

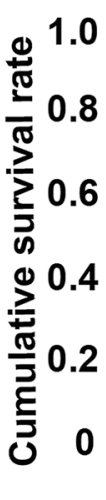

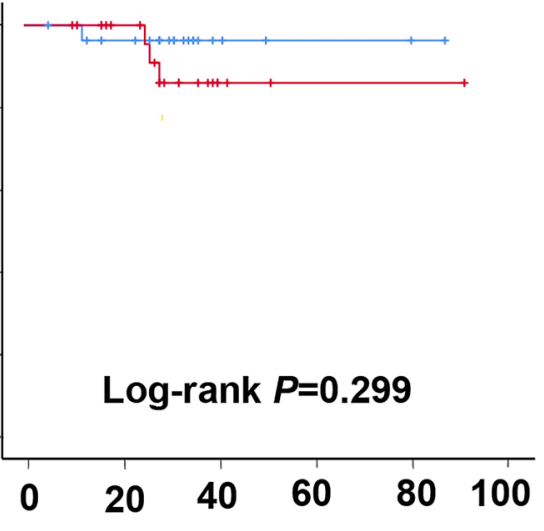

Time after operation (months)
pTNM I

$\neg$ OTG

ILATG

†OTG censored

+LATG censored
C

Before PSM

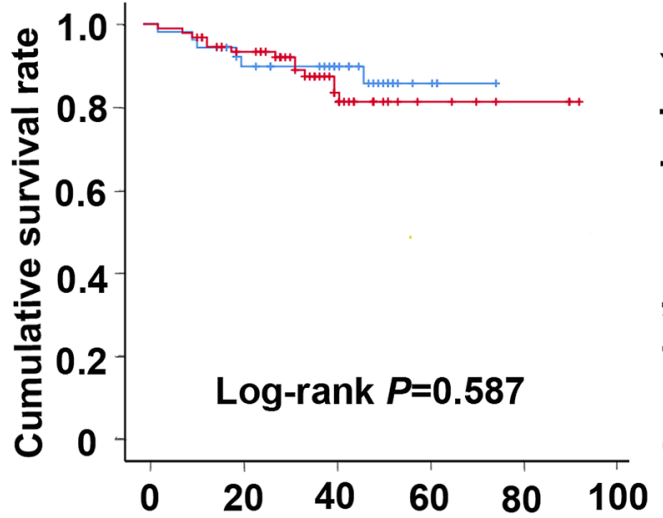

Time after operation (months)
D

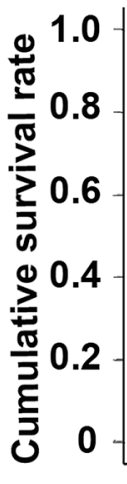

After PSM

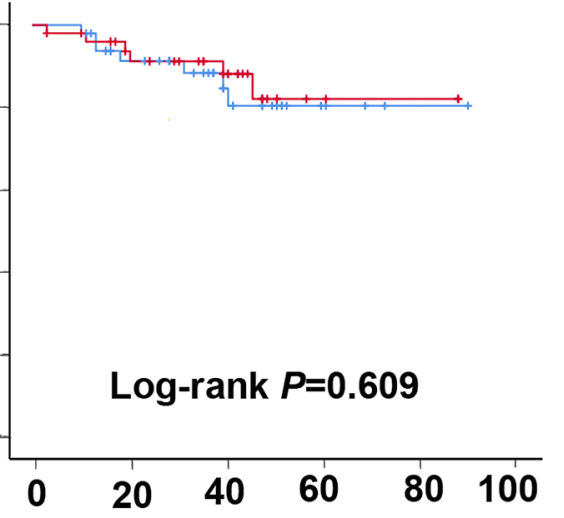

Time after operation (months)

PTNM II $\rightarrow$ OTG

- OTG censored + LATG censored

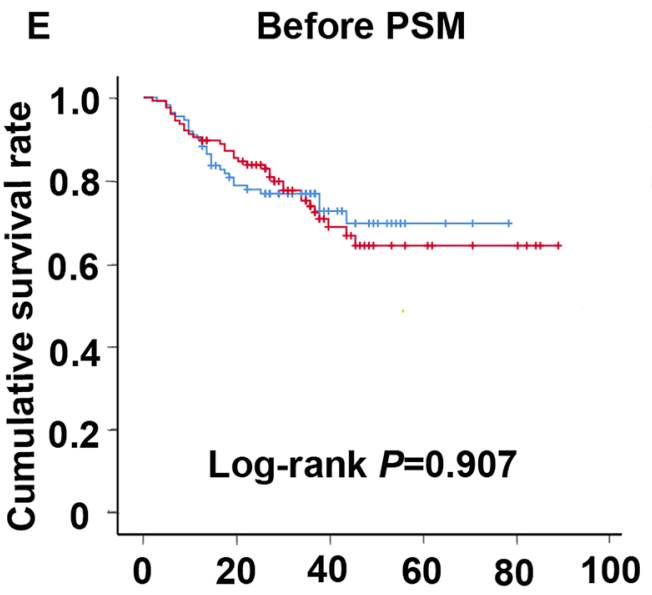

Time after operation (months)
$\mathbf{F}$

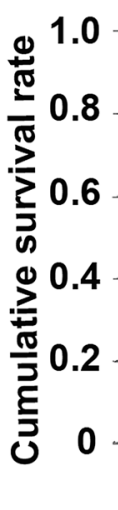

Time after operation (months)
PTNM III

$\neg$ OTG

$\neg$ LATG

+OTG censored

+ LATG censored 
Table 5 Univariate and multivariate analyses of risk factors of overall survival after PSM

\begin{tabular}{|c|c|c|c|c|c|c|}
\hline \multirow[t]{2}{*}{ Variables } & \multicolumn{2}{|c|}{ Univariate analysis } & \multirow[t]{2}{*}{$P$} & \multicolumn{2}{|c|}{ Multivariate analysis } & \multirow[t]{2}{*}{$P$} \\
\hline & HR & $95 \% \mathrm{CI}$ & & HR & $95 \% \mathrm{CI}$ & \\
\hline \multicolumn{7}{|l|}{ Surgical procedure } \\
\hline OTG & 1 [Reference] & & & & & \\
\hline LATG & 0.969 & $0.589-1.594$ & 0.901 & & & \\
\hline \multicolumn{7}{|l|}{ Age (years) } \\
\hline$<60$ & 1 [Reference] & & & & & \\
\hline$\geq 60$ & 0.727 & $0.437-1.207$ & 0.218 & & & \\
\hline \multicolumn{7}{|l|}{ Gender } \\
\hline Female & 1 [Reference] & & & & & \\
\hline Male & 0.980 & $0.548-1.754$ & 0.946 & & & \\
\hline \multicolumn{7}{|l|}{ BMI } \\
\hline$<30$ & 1 [Reference] & & & 1 [Reference] & & \\
\hline$\geq 30$ & 0.363 & $0.113-1.166$ & 0.089 & 2.521 & $0.782-8.125$ & 0.121 \\
\hline \multicolumn{7}{|l|}{ ASA } \\
\hline$<3$ & 1 [Reference] & & & & & \\
\hline$\geq 3$ & 1.058 & $0.384-2.914$ & 0.913 & & & \\
\hline \multicolumn{7}{|l|}{ NAC } \\
\hline No & 1 [Reference] & & & & & \\
\hline Yes & 0.749 & $0.340-1.647$ & 0.472 & & & \\
\hline \multicolumn{7}{|l|}{ pTNM } \\
\hline $\mathrm{I} / \mathrm{II}$ & 1 [Reference] & & & 1 [Reference] & & \\
\hline III & 2.836 & $1.623-4.957$ & $<0.001$ & 2.678 & $1.385-5.177$ & 0.003 \\
\hline \multicolumn{7}{|l|}{ Macroscopic appearance } \\
\hline Non-linitis plastica & 1 [Reference] & & & & & \\
\hline Linitis plastica & 0.618 & $0.294-1.300$ & 0.204 & & & \\
\hline Blood loss in surgery $(\mathrm{ml})$ & 0.999 & $0.996-1.002$ & 0.703 & & & \\
\hline Time of surgery (min) & 1.002 & $0.997-1.006$ & 0.501 & & & \\
\hline \multicolumn{7}{|l|}{ Postoperative complication } \\
\hline No & 1 [Reference] & & & & & \\
\hline Yes & 0.777 & $0.428-1.409$ & 0.405 & & & \\
\hline \multicolumn{7}{|l|}{ Vascular cancer embolus } \\
\hline$(-)$ & 1 [Reference] & & & 1 [Reference] & & \\
\hline$(+)$ & 0.601 & $0.347-1.040$ & 0.069 & 0.936 & $0.490-1.789$ & 0.842 \\
\hline CEA (ng/ml) & 1.006 & $1.002-1.010$ & 0.004 & 1.002 & $0.995-1.010$ & 0.572 \\
\hline CA199 (U/ml) & 1.000 & $1.000-1.001$ & 0.455 & & & \\
\hline CA72-4 (U/ml) & 1.001 & $1.001-1.002$ & 0.002 & 1.001 & $0.999-1.003$ & 0.417 \\
\hline
\end{tabular}

Bold and italic values are statistically significant $p<0.05$

$L A T G$ laparoscopic-assisted total gastrectomy, OTG open total gastrectomy, BMI body mass index, ASA American Society of Anesthesiologist, $N A C$ neoadjuvant chemotherapy, $C E A$ carcinoembryonic antigen, CA199 carbohydrate antigen $199, C A 72-4$ carbohydrate antigen $72-4, H R$ hazard ratio, $C I$ confidence interval et al. 2016). However, the smaller size of the abdominal incision in laparoscopic surgery may cause difficulties to adjust the stapler's angle in the esophagojejunostomy and lead to increased tension and potential bleeding risk in the anastomosis. In addition, a small incision makes it difficult to suture and reinforce the anastomosis, compared with conventional open surgery. Therefore, extra examination methods, such as intraoperative endoscopy examination or observation of the color of fluid draining through the gastrointestinal decompression tube and hand-sewing were recommended (Kim et al. 2012; Lee et al. 2017).

Anastomotic leakage is one of the main causes of mortality after surgery. In our study, the incidence of anastomotic leakage was higher in LATG than OTG group after PSM (4.6\% vs. $0.8 \%, P=0.120$ ). Although without statistical significance, the results are consistent with the previous studies (Sakamoto et al. 
Fig. 3 Forest graph of risk factors from multivariate COX analysis of overall survival. In the multivariate analysis, pTNM-III $(P=0.003)$ was significant risk factors of OS. $O S$ overall survival, $H R$ hazard ratio, $C I$ confidence interval, $B M I$ body mass index, $p T N M$ pathological TNM stage, $C E A$ carcinoembryonic antigen, CA72-4 carbohydrate antigen $72-4$
Risk factors of multivariate COX analysis of OS

$\mathrm{HR}(95 \% \mathrm{Cl})$

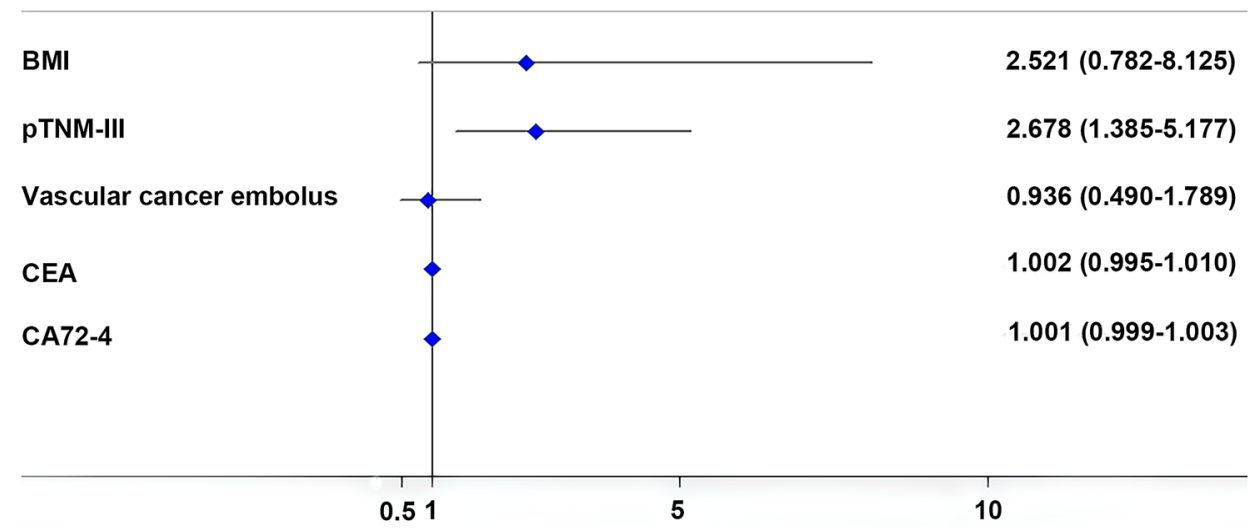

2019; Petersen et al. 2013). The complication rate of anastomotic leakage has been reported to be around $1.5-7.4 \%$ in LATG (Etoh et al. 2018; Jeong et al. 2009; Lee et al. 2015). A Japanese nationwide inpatient database analysis study (Sakamoto et al. 2019) explained that the higher rate of anastomotic leakage in LATG was mainly due to the difficulty in laparoscopic esophagojejunostomy, which may cause increased tension and insufficient blood supply of the anastomosis. The two most serious cases in our study with anastomotic leakage, who underwent a second surgery for exploratory laparotomy and debridement or thoracotomy and debridement respectively, were mainly due to increased tension caused by the retraction of the location of anastomotic stoma, which went to the inferior mediastinum. Besides, the different types of esophagojejunostomy which could reduce the anastomotic leakage rates are needed in future studies (Athanasiou et al. 2019; Gong and Li 2017; Montenovo et al. 2011).

In the univariate and multivariate analyses, age turned out to be an independent risk factor for postoperative complications. Nowadays, aging issue has become an increasingly prominent problem around the whole world (Li et al. 2017; Pal et al. 2010). The elderly patients showed less tolerance to invasive treatments due to increased possibility of more comorbidities and reduced reserve capacity of organs. Some studies reported the elderly are highly associated with postoperative complications and unplanned reoperation (Jung et al. 2015; Li et al. 2017; Su et al. 2011). The application of LATG to elderly patients remains controversial and needs further studies.

With regard to the long-term survival, our data showed a comparable 5-year overall survival rate between LATG and OTG group in all subgroup analyses. Even for the highly advanced stage, especially stage III, the prognosis showed no significant difference between the laparoscopic group and open group. Therefore, long-term survival will not be influenced by surgical types in each pathological stage, which was in accordance with other studies (Lee et al. 2013; Lin et al. 2017). The independent risk factor for overall survival analyzed by multiple COX regression was pathological stage. Our results also indicated that GC patients of stage III had a higher risk to develop worse prognosis than stage I and II. Nowadays, with the application of adjuvant chemotherapy, which is routinely used for AGC, the prognosis of gastric cancer is better than before, while more studies are needed to achieve a better prognosis.

The main limitation of the present study was that it was a single center retrospective study with limited cases. Although the potential selection bias had been minimized using PSM, which increased the reliability of this study, a risk of underpowered statistical analysis could not be avoided because of the reduced sample size after PSM. Therefore, a multicenter RCT study is expected to draw more accurate and convincing conclusions.

\section{Conclusion}

In conclusion, LATG performed by experienced surgeons could provide comparable surgical safety and survival outcomes with OTG for GC patients.

Author contributions YF: Conceptualization, Writing-Original Draft, Software, Formal analysis; ML: Conceptualization, Data Curation; SL: Formal analysis, Writing-Review and Editing; JY: Data Curation; XQ: Visualization; FT: Methodology; KX: Software; NZ: Methodology; ZY: Software; HY: Methodology; CZ: Methodology; JX: Methodology, Software; ZW: Conceptualization, Software, Writing-Review and Editing; MC: Conceptualization, Writing-Review and Editing; XS: Conceptualization, Supervision.

Funding This study was supported by the National Natural Science Foundation of China (nos. 81872022, 81672439, 82073357), Beijing Natural Science Foundation (no. 7162039), Capital's Funds for Health Improvement and Research (CFH 2018-2-2153).

Availability of data and material The datasets used in this study are available from the corresponding author on reasonable request. 


\section{Compliance with ethical standards}

Conflict of interest All authors declare that there is no conflict of interest.

Open Access This article is licensed under a Creative Commons Attribution 4.0 International License, which permits use, sharing, adaptation, distribution and reproduction in any medium or format, as long as you give appropriate credit to the original author(s) and the source, provide a link to the Creative Commons licence, and indicate if changes were made. The images or other third party material in this article are included in the article's Creative Commons licence, unless indicated otherwise in a credit line to the material. If material is not included in the article's Creative Commons licence and your intended use is not permitted by statutory regulation or exceeds the permitted use, you will need to obtain permission directly from the copyright holder. To view a copy of this licence, visit http://creativecommons.org/licenses/by/4.0/.

\section{References}

Athanasiou A, Spartalis M, Spartalis E (2019) Hybrid minimally invasive esophagectomy for esophageal cancer. N Engl J Med 380:152-162. https://doi.org/10.1056/NEJMc1901650

Austin PC (2009) Some methods of propensity-score matching had superior performance to others: results of an empirical investigation and Monte Carlo simulations. Biom J J Math Methods Biosci 51:171-184. https://doi.org/10.1002/bimj.200810488

Bray F, Ferlay J, Soerjomataram I, Siegel RL, Torre LA, Jemal A (2018) Global cancer statistics 2018: Globocan estimates of incidence and mortality worldwide for 36 cancers in 185 countries. CA Cancer J Clin 68:394-424. https://doi.org/10.3322/caac.21492

Davenport DL, Bowe EA, Henderson WG, Khuri SF, Mentzer RM (2006) National surgical quality improvement program (NSQIP) risk factors can be used to validate American Society of Anesthesiologists physical status classification (ASA PS) levels. Ann Surg 243:636-644. https://doi.org/10.1097/01.sla.0000216508.95556.cc

Diamantis T, Tsiminikakis N, Skordylaki A, Samiotaki F, Vernadakis $\mathrm{S}$, Bongiorni $\mathrm{C}$ et al (2007) Alterations of hemostasis after laparoscopic and open surgery. Hematology 12:561-570. https://doi. org/10.1080/10245330701554623

Dindo D, Demartines N, Clavien PA (2004) Classification of surgical complications: a new proposal with evaluation in a cohort of 6336 patients and results of a survey. Ann Surg 240:205-213. https://doi. org/10.1097/01.sla.0000133083.54934.ae

Etoh T, Honda M, Kumamaru H, Miyata H, Yoshida K, Kodera Y et al (2018) Morbidity and mortality from a propensity score-matched, prospective cohort study of laparoscopic versus open total gastrectomy for gastric cancer: data from a nationwide web-based database. Surg Endosc 32:2766-2773. https://doi.org/10.1007/s0046 4-017-5976-0

Gong W, Li J (2017) Combat with esophagojejunal anastomotic leakage after total gastrectomy for gastric cancer: a critical review of the literature. Int J Surg 47:18-24. https://doi.org/10.1016/j. ijsu.2017.09.019

Hang C, Chia-Wen H, Clymer JW, Schwiers ML, Tibensky BN, Leena P et al (2015) Gastrectomy and D2 lymphadenectomy for gastric cancer: a meta-analysis comparing the harmonic scalpel to conventional techniques. Int J Surg Oncol. https://doi.org/10.1155/2015/397260

He HY, Li HJ, Su XQ, Li ZY, Yu PW, Huang H et al (2018) Study on safety of laparoscopic total gastrectomy for clinical stage I gastric cancer: the protocol of the CLASS02-01 multicenter randomized controlled clinical trial. BMC Cancer 18:944. https://doi. org/10.1186/s12885-018-4846-Z
Herrera-Almario G, Strong VE (2016) Minimally invasive gastric surgery. Ann Surg Oncol 23:3792-3797. https://doi.org/10.1245/s1043 4-016-5429-3

Hiki N, Katai H, Mizusawa J, Nakamura K, Nakamori M, Yoshikawa $\mathrm{T}$ et al (2018) Long-term outcomes of laparoscopy-assisted distal gastrectomy with suprapancreatic nodal dissection for clinical stage I gastric cancer: a multicenter phase II trial (JCOG0703). Gastric Cancer 21:155-161. https://doi.org/10.1007/s10120-016-0687-0

Hu YF, Huang CM, Sun YH, Su XQ, Cao H, Hu JK et al (2016) Morbidity and mortality of laparoscopic versus open D2 distal gastrectomy for advanced gastric cancer: a randomized controlled trial. J Clin Oncol 34:1350-1357. https://doi.org/10.1200/JCO.2015.63.7215

Hyung WJ, Yang HK, Han SU, Lee YJ, Park JM, Kim JJ et al (2019) A feasibility study of laparoscopic total gastrectomy for clinical stage I gastric cancer: a prospective multi-center phase II clinical trial, KLASS 03. Gastric Cancer 22:214-222. https://doi.org/10.1007/ s10120-018-0864-4

Japanese Gastric Cancer Association (2017) Japanese gastric cancer treatment guidelines 2014 (ver. 4). Gastric Cancer 20:1-19. https ://doi.org/10.1007/s10120-016-0622-4

Jeong GA, Cho GS, Kim HH, Lee HJ, Ryu SW, Song KY (2009) Laparoscopy-assisted total gastrectomy for gastric cancer: a multicenter retrospective analysis. Surgery 146:469-474. https://doi. org/10.1016/j.surg.2009.03.023

Jung HS, Park YK, Ryu SY, Jeong O (2015) Laparoscopic total gastrectomy in elderly patients ( $\geq 70$ years) with gastric carcinoma: a retrospective study. J Gastric Cancer 15:176-182. https://doi. org/10.5230/jgc.2015.15.3.176

Katai H, Sasako M, Fukuda H, Nakamura K, Hiki N, Saka M et al (2010) Safety and feasibility of laparoscopy-assisted distal gastrectomy with suprapancreatic nodal dissection for clinical stage I gastric cancer: a multicenter phase II trial (JCOG0703). Gastric Cancer 13:238-244. https://doi.org/10.1007/s10120-010-0565-0

Katai H, Mizusawa J, Katayama H, Kunisaki C, Sakuramoto S, Inaki $\mathrm{N}$ et al (2019) Single-arm confirmatory trial of laparoscopyassisted total or proximal gastrectomy with nodal dissection for clinical stage I gastric cancer: Japan Clinical Oncology Group study JCOG1401. Gastric Cancer 22:999-1008. https://doi.org/10.1007/ s10120-019-00929-9

Kataoka K, Katai H, Mizusawa J, Katayama H, Nakamura K, Morita $S$ et al (2016) Non-randomized confirmatory trial of laparoscopyassisted total gastrectomy and proximal gastrectomy with nodal dissection for clinical stage I gastric cancer: Japan Clinical Oncology Group Study JCOG1401. J Gastric Cancer 16:93-97. https://doi. org/10.5230/jgc.2016.16.2.93

Kim KH, Kim MC, Jung GJ, Jang JS, Choi SR (2012) Endoscopic treatment and risk factors of postoperative anastomotic bleeding after gastrectomy for gastric cancer. Int J Surg 10:593-597. https://doi. org/10.1016/j.ijsu.2012.09.026

Kim W, Kim HH, Han SU, Kim MC, Hyung WJ, Ryu SW et al (2016) Decreased morbidity of laparoscopic distal gastrectomy compared with open distal gastrectomy for stage I gastric cancer: short-term outcomes from a multicenter randomized controlled trial (KLASS01). Ann Surg 263:28-35. https://doi.org/10.1097/SLA.00000 00000001346

Kofoed SC, Calatayud D, Jensen LS, Helgstrand F, Achiam MP, Heer PD et al (2015) Intrathoracic anastomotic leakage after gastroesophageal cancer resection is associated with increased risk of recurrence. J Thorac Cardiovasc Surg 150:42-48. https://doi.org/10.1016/j.jtcvs .2015.04.030

Lattouf JB, Beri A, Klinger CH, Jeschke S, Janetschek G (2007) Practical hints for hemostasis in laparoscopic surgery. Minim Invasive Ther Allied Technol 16:45-51. https://doi.org/10.1080/1364570060 1157984

Lee JH, Ahn SH, Park DJ, Kim HH, Lee HJ, Yang HK (2012) Laparoscopic total gastrectomy with D2 lymphadenectomy for advanced 
gastric cancer. World J Surg 36:2394-2399. https://doi.org/10.1007/ s00268-012-1669-y

Lee MS, Lee JH, Park DJ, Lee HJ, Kim HH, Yang HK (2013) Comparison of short- and long-term outcomes of laparoscopic-assisted total gastrectomy and open total gastrectomy in gastric cancer patients. Surg Endosc 27:2598-2605. https://doi.org/10.1007/s0046 4-013-2796-8

Lee JH, Nam BH, Ryu KW, Ryu SY, Park YK, Kim S et al (2015) Comparison of outcomes after laparoscopy-assisted and open total gastrectomy for early gastric cancer. Br J Surg 102:1500-1505. https ://doi.org/10.1002/bjs.9902

Lee S, Ahn JY, Na S, Na HK, Jung KW, Kim DH et al (2017) Clinical features of postoperative anastomotic bleeding after gastrectomy and efficacy of endoscopic hemostasis: a case-control study. Surg Endosc 31:3210-3218. https://doi.org/10.1007/s00464-016-5347-2

Li P, Huang CM, Tu RH, Lin JX, Lu J, Zheng CH et al (2017) Risk factors affecting unplanned reoperation after laparoscopic gastrectomy for gastric cancer: experience from a high-volume center. Surg Endosc 31:3922-3931. https://doi.org/10.1007/s00464-017-5423-2

Lin JX, Lin JL, Zheng CH, Ping Li, Xie JW, Wang JB et al (2017) Shortand long-term outcomes of laparoscopy-assisted versus open total gastrectomy for gastric cancer: a propensity score-matched analysis. Oncotarget 8:80029-80038. https://doi.org/10.18632/oncotarget .16852

Montenovo MI, Chambers K, Pellegrini CA, Oelschlager BK (2011) Outcomes of laparoscopic-assisted transhiatal esophagectomy for adenocarcinoma of the esophagus and esophago-gastric junction. Dis Esophagus 24:430-436. https://doi.org/10.111 1/j.1442-2050.2010.01165.x

Nagasako Y, Satoh S, Isogaki J, Inaba K, Taniguchi K, Uyama I (2012) Impact of anastomotic complications on outcome after laparoscopic gastrectomy for early gastric cancer. Br J Surg 99:849-854. https:// doi.org/10.1002/bjs.8730

Nakamura K, Katai H, Mizusawa J, Yoshikawa T, Ando M, Terashima M et al (2013) A phase III study of laparoscopy-assisted versus open distal gastrectomy with nodal dissection for clinical stage IA/IB gastric cancer (JCOG0912). Jpn J Clin Oncol 43:324-327. https:// doi.org/10.1093/jjco/hys220

Pal SK, Katheria V, Hurria A (2010) Evaluating the older patient with cancer: understanding frailty and the geriatric assessment. CA Cancer J Clin 60:120-132. https://doi.org/10.3322/caac.20059

Park YK, Yoon HM, Kim YW, Park JY, Ryu KW, Lee YJ et al (2018) Laparoscopy-assisted versus open D2 distal gastrectomy for advanced gastric cancer: results from a randomized phase II multicenter clinical trial (COACT 1001). Ann Surg 267:638-645. https ://doi.org/10.1097/SLA.0000000000002168

Petersen TI, Pathle E, Sommer T, Zilling T (2013) Laparoscopic minimally invasive total gastrectomy with linear stapled oesophagojejunostomy - experience from the first thirty procedures. Anticancer Res 33:3269-3273. https://doi.org/10.3109/0284186X.2013.80682 0

Pugliese R, Maggioni D, Sansonna F, Costanzi A, Ferrari GC, Lernia SD et al (2010) Subtotal gastrectomy with D2 dissection by minimally invasive surgery for distal adenocarcinoma of the stomach: results and 5-year survival. Surg Endosc 24:2594-2602. https://doi. org/10.1007/s00464-010-1014-1

Ralph BD (1998) Propensity score methods for bias reduction in the comparison of a treatment to a non-randomized control group. Stat Med 17:2265-2281. https://doi.org/10.1002/(sici)1097-0258(19981 015) $17: 19$
Rosenbaum PR (1983) The central role of the propensity score in observational studies for causal effects. Biometrika 70:41-55. https://doi. org/10.1093/biomet/70.1.41

Sakamoto T, Fujiogi M, Matsui H, Fushimi K, Yasunaga H (2019) Shortterm outcomes of laparoscopic and open total gastrectomy for gastric cancer: a nationwide retrospective cohort analysis. Ann Surg Oncol 27:518-526. https://doi.org/10.1245/s10434-019-07688-y

Sakuramoto S, Yamashita K, Kikuchi S, Futawatari N, Katada N, Watanabe $\mathrm{M}$ et al (2013) Laparoscopy versus open distal gastrectomy by expert surgeons for early gastric cancer in Japanese patients: short-term clinical outcomes of a randomized clinical trial. Surg Endosc 27:1695-1705. https://doi.org/10.1007/s00464-012-2658-9

Sano T, Coit DG, Kim HH, Roviello F, Kassab P, Wittekind C et al (2017) Proposal of a new stage grouping of gastric cancer for TNM classification: International Gastric Cancer Association staging project. Gastric Cancer 20:217-225. https://doi.org/10.1007/s1012 0-016-0601-9

Shim JH, Oh SI, Yoo HM, Jeon HM, Park CH, Song KY (2013) Shortterm outcomes of laparoscopic versus open total gastrectomy: a matched-cohort study. Am J Surg 206:346-351. https://doi. org/10.1016/j.amjsurg.2012.11.011

Shinohara T, Kanaya S, Taniguchi K, Fujita T, Yanaga K, Uyama I (2009) Laparoscopic total gastrectomy with D2 lymph node dissection for gastric cancer. Arch Surg 144:1138-1142. https://doi. org/10.1001/archsurg.2009.223

Sierzega M, Kolodziejczyk P, Kulig J, Polish Gastric Cancer Study Group (2010) Impact of anastomotic leakage on long-term survival after total gastrectomy for carcinoma of the stomach. Br J Surg 97:1035-1042. https://doi.org/10.1002/bjs.7038

Su HS, Hur H, Chang WA, Xian Y, Yong KC (2011) Operative risk factors in gastric cancer surgery for elderly patients. J Gastric Cancer 11:116-121. https://doi.org/10.5230/jgc.2011.11.2.116

Szold A, Miller A, Lilach N, Botero-Anug AM, Miller R, Schwaitzberg SD (2018) A preclinical animal study of a novel, simple, and secure duct and vessel occluder for laparoscopic surgery. Surg Endosc 32:3311-3320. https://doi.org/10.1007/s00464-018-6052-0

Vecchio R, Catalano R, Basile F, Spataro C, Caputo M, Intagliata E (2016) Topical hemostasis in laparoscopic surgery. G Chir 27:266270. https://doi.org/10.11138/gchir/2016.37.6.266

Wang ZZ, Xing JD, Cai J, Zhang ZT, Li F, Zhang NW et al (2019) Shortterm surgical outcomes of laparoscopy-assisted versus open D2 distal gastrectomy for locally advanced gastric cancer in north China: a multicenter randomized controlled trial. Surg Endosc 33:33-45. https://doi.org/10.1007/s00464-018-6391-x

Yoo HM, Lee HH, Shim JH, Jeon HM, Park CH, Song KY (2011) Negative impact of leakage on survival of patients undergoing curative resection for advanced gastric cancer. J Surg Oncol 104:734-740. https://doi.org/10.1002/jso.22045

Yu J, Huang CM, Sun YH, Su XQ, Cao H, Hu JK et al (2019) Effect of laparoscopic vs open distal gastrectomy on 3-year diseasefree survival in patients with locally advanced gastric cancer: the CLASS-01 randomized clinical trial. JAMA 321:1983-1992. https ://doi.org/10.1001/jama.2019.5359

Zeng YK, Yang ZL, Peng JS, Lin HS, Cai L (2012) Laparoscopyassisted versus open distal gastrectomy for early gastric cancer: evidence from randomized and nonrandomized clinical trials. Ann Surg 256:39-52. https://doi.org/10.1097/SLA.0b013e3182583e2e

Publisher's Note Springer Nature remains neutral with regard to jurisdictional claims in published maps and institutional affiliations. 